\title{
Linking Research and Practice: Effective Strategies for Teaching Vocabulary in the ESL Classroom
}

Jihyun Nam

Vocabulary plays a pivotal role in the ESL classroom. Whereas a considerable amount of research has examined effective ESL vocabulary teaching and learning, missing are studies that provide examples of how to put various research findings into practice: that is, apply them to real texts including target vocabulary items. In order to close the gap between research and practice, I reviewed a broad range of relevant literature addressing vocabulary learning. Drawing on an authentic Web reading text, in which I selected five vocabulary items as target words on the basis of my experience as a secondary English teacher in Korea, I applied vocabulary teaching strategies drawn from research findings reported in the literature to provide a model for ESL teachers when putting theory into practice.

Le vocabulaire joue un rôle critique dans la salle de classe ALS. Alors qu'une quantité importante de recherche a porté sur l'enseignement et l'apprentissage du vocabulaire en ALS, il manque des études qui évoquent des exemples de la mise en pratique de ces résultats de recherche; c'est-à-dire, leur application à de véritables textes qui contiennent des éléments de vocabulaire ciblés. En vue de réduire l'écart entre la recherche et la pratique, j'ai fait une revue étendue de la littérature pertinente sur l'apprentissage du vocabulaire. Puisant dans un texte authentique tiré $d u$ Web, j'ai choisi, en fonction de mon expérience comme enseignant d'anglais dans une école secondaire en Corée, cinq items de vocabulaire comme mots cibles. Par la suite, j'ai appliqué des stratégies d'enseignement du vocabulaire tirées de résultats de recherche pour proposer aux enseignants d'ALS un modèle qui vise la mise en pratique de la théorie.

\section{Introduction}

In the ESL context, vocabulary not only supports the four language skills, listening, speaking, reading, and writing, but also mediates between ESL students and content-area classes in that these students often find that lack of vocabulary knowledge is an obstacle to learning. Therefore, it follows that ESL vocabulary teaching and learning are often emphasized. In a similar fashion, if ESL teachers are attuned to effective strategies for teaching vocabulary, they could facilitate students' proficiency in the four skills. A review of the literature on ESL vocabulary shows that whereas most studies have focused on effective teaching and learning, lacking are studies that provide 
examples of how to put various research findings into practice. Moreover, empirical research often focuses on a limited number of specific strategies, whereas classroom practice is more complex and uses a variety of strategies. The present study highlights the importance of bridging the gap between research and practice.

I begin by reviewing a broad range of relevant literature that addresses various aspects of second-language (L2) vocabulary teaching and learning: for example, intentional and incidental vocabulary learning, vocabulary retention, and vocabulary learning through diverse activities or tasks. In order to provide a model for ESL teachers to apply theories and insights provided by others in their own classrooms, I then apply some vocabularyteaching strategies drawn from research findings to an authentic Web reading text in which certain vocabulary items are assumed to be difficult for ESL students to comprehend.

\section{Earlier Research on Teaching and Learning L2 Vocabulary}

Read (2004) noted that in studies on L2 vocabulary learning, a distinction had long been made between incidental and intentional learning, with the main focus on the former, especially exploring the extent to which students can learn vocabulary items incidentally while engaging in other language-learning activities. Furthermore, to augment incidental vocabulary-learning in the ESL classroom, it would be effective for teachers to provide students with target vocabulary items through tasks, as well as to ask them to read only the texts that include the target words. For example, students can read and retell a text generatively, that is, in their own words (Joe, 1998). Also, in order to learn unknown words while reading a text, students can access a dictionary with various look-up options such as pictorial and verbal cues (Laufer \& Hill, 2000).

With regard to vocabulary retention, Hulstijn (1992) demonstrated that target vocabulary items were retained significantly longer when their meanings were correctly inferred than when explained by their synonyms. Joe (1995) argued that the retention of unfamiliar words was significantly facilitated when students engaged in a text-based task that demanded a higher level of generativity. Similarly, Hulstijn and Laufer (2001) demonstrated that EFL students who participated in a composition task could retain target words better than those engaged in a reading comprehension or fill-in task, which suggests that students who were involved in higher levels of vocabulary production-processing remembered target words better than those who were not. Plass, Chun, Mayer, and Leutner (1998) stated that students remembered unknown words better when provided with both pictorial and written annotations than when provided with only one kind or no annotation. 
Considerable research has recently been conducted into the effectiveness of vocabulary teaching and learning through various activities or tasks. Lee and Muncie (2006) showed that a post-reading composition task helped ESL students improve the productive use of higher-level target vocabulary. Newton (1995) pointed out that students made more vocabulary gains when engaging in communicative tasks that demanded interactions than when negotiating word meanings explicitly. Wesche and Paribakht (2000) demonstrated that students learned vocabulary more effectively when they engaged in text-based vocabulary exercises in addition to reading a text than when they read multiple texts without exercises, because in the latter case, they could learn not only target words, but also their lexical features. Further, Folse (2006) suggested that how frequently students retrieved unfamiliar words influenced their retention more than how deeply they were involved in processing them, which demonstrates that students could improve their retention of new target words more while engaging in multiple fill-in-theblank exercises than while writing one original sentence with each target word. Finally, Nassaji (2003) suggested that ESL students might grope ineffectively for lexical inferences about word meanings from context, so that teachers should provide them with a chance to identify and define exact meanings for unknown words.

\section{Applying Vocabulary-Teaching Strategies to an Authentic Text}

Although a considerable number of studies on L2 vocabulary teaching and learning are available, lacking are examples of how teachers can apply the various research findings of scholars to their own teaching materials. In order not only to bridge the gap between theory and practice, but also to provide a springboard for ESL teachers' design of vocabulary teaching materials, I have developed various activities and tasks for vocabulary teaching and learning that apply effective strategies drawn from others' research findings to an authentic Web text, as follows (text drawn from the NASA Web site; the five underlined words are the target vocabulary items).

What can you do to help save water?

You can help preserve and protect water. Use these helpful tips at home and school.

- Don't leave the water running while you're brushing your teeth or washing the dishes.

- Take shorter showers. Keep an egg timer in the bathroom and see who in your family can shorten their showers to 3 minutes.

- Help your mom or dad fix a dripping faucet. Did you know that it can waste 20 gallons of water a day?

- Fill a pitcher with tap water and put it in the fridge, rather than running the tap every time you want a cold drink. 
- Clean sidewalks and driveways with a broom. You can help save water by not using the garden hose.

- Help your mom or dad water the lawn in the early morning to avoid evaporation, and place a layer of mulch around trees and plants to retain water.

- Stop throwing away so many batteries. The mercury in old batteries can eventually leak out and poison the water it runs into. What can you do? Buy rechargeable alkaline batteries. They can be charged 25 times. That means 25 batteries you don't have to buy and throw away! (National Aeronautics and Space Administration, 2008, p. 9)

\section{Pictorial Vocabulary Teaching}

Underpinned by Nassaji's (2003) idea of the fallibility of inferring the meanings of unknown words from pictures, and by Plass et al.'s (1998) suggestion of using both pictorial and written annotations, target vocabulary items can be provided with their equivalent pictures and written annotations, as shown in Figure 1.

Jiang (2004) asserted that adult L2 learners could draw on the mature conceptual and lexical systems of their native languages (L1s), in part because target vocabulary items usually have corresponding words in L1s.

Target
Words

Pictures
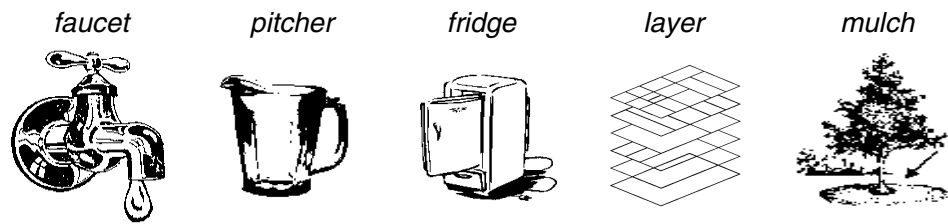

Annotations

of

Words
- faucet: the thing that you turn on and off to control the flow of water from a pipe, e.g., The faucet is leaking.

- pitcher: a container used for holding and pouring liquids, with a handle and a spout e.g., a pitcher of beer.

- fridge: an informal expression for a refrigerator e.g., Keep the milk and butter in the fridge.

- layer: something that is placed on or between other things e.g., several layers of clothing

- mulch: decaying leaves that you put on the soil to improve its quality and to protect the roots of plants e.g., You had better lay mulch on the soil around the plants to retain moisture.

Figure 1. Target vocabulary items provided with their corresponding pictures and annotations. 
Target

Words

Pictures
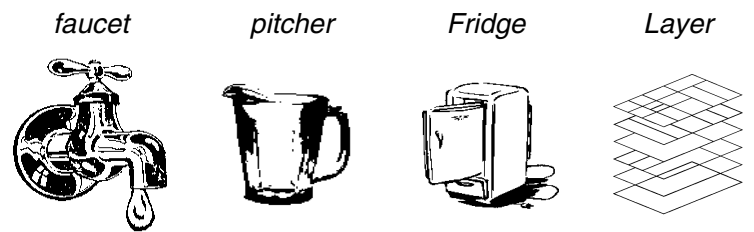

mulch

Korean

Words

sudo-kkogji picheo

naengjang-go cheung

jip

Figure 2. Target vocabulary items provided with their corresponding pictures and L1 items.

Fraser (1999) also found evidence that L2 students could significantly increase retention rates for unfamiliar target words by using their L1 knowledge of semantic and linguistic structures as a touchstone against which to judge those of the target words. Drawing on these ideas, an L2 vocabularyteaching strategy can be designed as shown in Figure 2. Although limited to situations where students share the same L1, it could certainly be used in the EFL context. Figure 2 shows the case in which students are Koreans.

\section{Fill-in Task}

Although open-ended tasks, discussed below, can contribute to students' vocabulary retention (Hulstijn \& Laufer, 2001), they involve highly productive processing and so may not be appropriate for students at the beginning or intermediate levels. A more controlled vocabulary-learning task such as a fill-in may better accommodate their linguistic competence. The following is an example of a fill-in task based on the given text.

\section{Fill-in task}

Instructions: Fill in each blank with the right word from the box below to complete the whole text. You will NOT use ALL the words.

drink, fridge, mulch, surface, bag, layer, faucet, glass, pitcher

What can you do to help save water?

You can help preserve and protect water. Use these helpful tips at home and school.

- Don't leave the water running while you're brushing your teeth or washing the dishes.

- Take shorter showers. Keep an egg timer in the bathroom and see who in your family can shorten their showers to 3 minutes.

- Help your mom or dad fix a dripping Did you know that it can waste 20 gallons of water a day?

- Fill a with tap water and put it in the rather than running the tap every time you want a cold drink.

- Clean sidewalks and driveways with a broom. You can help save water by not using the garden hose. 
- Help your mom or dad water the lawn in the early morning to avoid evaporation, and place a of around trees and plants to retain water.

- Stop throwing away so many batteries. The mercury in old batteries can eventually leak out and poison the water it runs into. What can you do? Buy rechargeable alkaline batteries. They can be charged 25 times. That means 25 batteries you don't have to buy and throw away!

A fill-in task may also be designed so that the sentences are connected to provide a summary of the text.

\section{Summarizing a text}

Instructions: The following is a summary of the given text. Fill in each blank with the right word to correspond with the given text.

You can save water if you use some helpful tips at home and school. First, you should not leave the water running while brushing your teeth or washing the dishes. Second, it is recommended that you use an egg timer to take shorter showers. Third, ask your parents to fix a dripping . Fourth, rather than running tap water whenever needed, you can keep it in the using $a$ . Fifth, use a broom instead of a garden hose to clean sidewalks and driveways. Sixth, in order to avoid evaporation and retain water longer around trees and plants, you can use a of __. Finally, use rechargeable alkaline batteries instead of old ones to avoid mercury pollution caused by old batteries.

\section{Post-Reading Composition Task}

Based on research findings (Hulstijn \& Laufer, 2001; Lee \& Muncie, 2006) that underscore the significant effects of students' productive use of unknown words and their involvement in high vocabulary production processing, a composition task can be designed as follows.

\section{Composition task}

Instructions: Write a letter to some of your friends in order to give them some tips on how to save water, based on what you have learned from the text. In your letter, you MUST use the FIVE target words (see "Annotations of Words" in Figure 1). You may decide yourself in which order you will use them. Regarding each word, its explanation and examples of usage are provided.

\section{Reading and Retelling Task}

As Joe $(1995,1998)$ demonstrated, retelling what we have read greatly improves vocabulary gains for unfamiliar words because it demands a higher level of generation. Such a task can be designed for the given text as follows.

$$
\text { Retelling a text }
$$

Instructions: Retell what you have read in the text to other students. You MUST use the five underlined words.

Composition and retelling tasks may be more appropriate for advanced students at a high level of English proficiency level than for those at other levels, because they presuppose a high level of speaking ability. Fill-in and 
summarizing tasks may be more appropriate for beginning- or intermediatelevel students.

\section{Vocabulary Exercises}

Because vocabulary gains for unknown words can be augmented more effectively when a reading text is accompanied by text-based vocabulary exercises than without them (Wesche \& Paribakht, 2000), teachers need to consider possible ways of developing exercises that students can carry out with new words to realize varied lexical features. Similarly, a matching exercise and a crossword puzzle can be designed with the target words as follows.

\section{Matching exercise}

Instructions: Match each vocabulary item on the left with its corresponding meaning on the right.

pitcher

an informal expression for a refrigerator

layer something that is placed on or between other things

mulch a container used for holding and pouring liquids, with a handle and a spout

faucet the thing that you turn on and off to control the flow of water from a pipe

fridge decaying leaves that you put on the soil to improve its quality and to protect the roots of plants

\section{Crossword puzzle}

Instructions: Complete the crossword puzzle using the given clues.

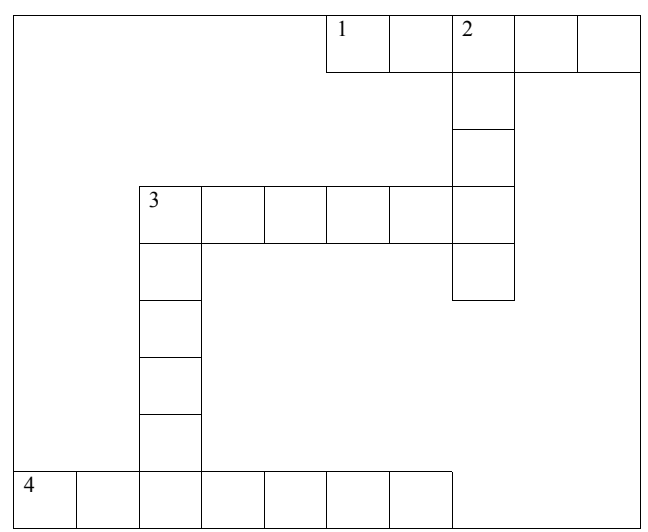

\section{Across}

1. Decaying leaves that you put on the soil to improve its quality and to protect the roots of plants

3. An informal expression for a refrigerator

4. A container used for holding and pouring liquids, with a handle and a spout

Down

2. Something that is placed on or between other things

3. The thing that you turn on and off to control the flow of water from a pipe 


\section{Conclusion}

This article presents various materials for ESL vocabulary-teaching that apply to an authentic text strategies drawn from research findings so that teachers can be encouraged to put theories or insights into practice similarly. One limitation of this advice lies in contradictions among research findings, for example, conflicting perspectives on the role of L1 equivalents in L2 vocabulary-learning. Moreover, the various vocabulary-teaching strategies developed in this study need to be variably applied to ESL students according to their proficiency levels. That is, whereas pictures and L1 equivalents and controlled fill-in tasks are more appropriate at the beginning and intermediate levels, less controlled tasks such as compositions and retellings may be more suitable for the advanced level.

Although the number of studies reviewed and employed here is limited, they do yield implications for ESL vocabulary-teaching that teachers may use as theoretical suggestions for creating materials. First, the use of visual representations such as pictures and drawings can promote vocabulary retention. Second, L1 translation equivalents, as in Figure 2, can promote L2 vocabulary-learning. Third, higher involvement in vocabulary production processing, for example, a composition task or retelling a text, can contribute to vocabulary retention. Finally, task-based vocabulary-learning through various activities can promote vocabulary learning.

\section{The Author}

Jihyun Nam is pursuing a doctoral degree in the Department of Literacy, Culture, and Language Education at Indiana University. His research areas include acquisition of second-language vocabulary, critical applied linguistics, critical pedagogy and literacy, critical discourse analysis, and critical ethnography. He has recently striven to link ESL/EFL instruction with critical perspectives.

\section{References}

Folse, K.S. (2006). The effect of type of written exercise on L2 vocabulary retention. TESOL Quarterly, 40, 273-293.

Fraser, C.A. (1999). Lexical processing strategy use and vocabulary learning through reading. Studies in Second Language Acquisition, 21, 225-241.

Hulstijn, J.H. (1992). Retention of inferred and given word meanings: Experiments in incidental vocabulary learning. In P.J. Arnaud \& H. Bejoint (Eds.), Vocabulary and applied linguistics (pp. 113-125). London: Macmillan.

Hulstijn, J.H., \& Laufer, B. (2001). Some empirical evidence for the involvement load hypothesis in vocabulary acquisition. Language Learning, 51, 539-558.

Jiang, N. (2004). Semantic transfer and its implications for vocabulary teaching in a second language. Modern Language Journal, 88, 416-432.

Joe, A. (1995). Text-based tasks and incidental vocabulary learning. Second Language Research, $11,149-158$.

Joe, A. (1998). What effects do text-based tasks promoting generation have on incidental vocabulary acquisition? Applied Linguistics, 19, 357-377. 
Laufer, B., \& Hill, M. (2000). What lexical information do L2 learners select in a CALL dictionary and how does it affect word retention? Language Learning and Technology, 3, 58-76.

Lee, S.H., \& Muncie, J. (2006). From receptive to productive: Improving ESL learners' use of vocabulary in a postreading composition task. TESOL Quarterly, 40, 295-320.

Nassaji, H. (2003). L2 vocabulary learning from context: Strategies, knowledge sources, and their relationship with success in L2 lexical inferencing. TESOL Quarterly, 37, 645-670.

National Aeronautics and Space Administration. (2008). Earth Day 2008: Children's Earth Day activity book. Retrieved May 10, 2008, from: http:/ / earthday.grc.nasa.gov/2008ActivityBook.pdf

Newton, J. (1995). Task-based interaction and incidental vocabulary learning: A case study. Second Language Research, 11, 159-177.

Plass, J.L., Chun, D.M., Mayer, R.E., \& Leutner, D. (1998). Supporting visual and verbal learning preferences in a second language multimedia learning environment. Journal of Educational Psychology, 90, 25-36.

Read, J. (2004). Research in teaching vocabulary. Annual Review of Applied Linguistics, 24, 146-161.

Wesche, M.B., \& Paribakht, T.S. (2000). Reading-based exercises in second language vocabulary learning: An introspective study. Modern Language Journal, 84, 196-213. 